\title{
Gratitude is Related to the Identity of the Benefactor
}

\author{
Shueh-Chin Ting ${ }^{1, *}$ \\ ${ }^{1}$ Department of Education, National University of Tainan, Taiwan \\ *Corresponding author: Department of Education, National University of Tainan, Taiwan. \\ E-mail: tingsc@ms49.hinet.net
}

Received: September 5, 2020 Accepted: November 19, 2020 Published: December 20, 2020

doi:10.5296/ije.v12i4.17640 URL: https://doi.org/10.5296/ije.v12i4.17640

\begin{abstract}
In the past, there has been a dearth of research exploring related factors regarding the benefactor in the research of gratitude. The focus of this study is to investigate whether different benefactors elicit different levels of gratitude in beneficiaries after conferring a favor. Using college students as the research subjects, questionnaires were conducted after subjects read the experimental text to explore whether college students' gratitude is different when two types of benefactors (friends and parents) give the same help. This study found that when the benefactor makes a big effort to confer a favor and the favor is very important to the beneficiary, there is no significant difference in the gratitude toward their parents and friends among college students and the level of gratitude for both is very high. However, when the favor only is conferred through an ordinary amount of effort and the favor is of ordinary importance to the beneficiary, college students have a higher level of gratitude to their friends, but a lower level of gratitude to their parents. Therefore, college students do not necessarily have higher gratitude to their friends than to their parents; the amount of effort exerted by the benefactor and the importance of the favor to the beneficiary are two key factors.
\end{abstract}

Keywords: benefactor, beneficiary, friend, gratitude, parent 


\section{Research Motives}

Although gratitude is an old concept, research on the topic of gratitude has only received widespread attention in the past decade. Even though there have been many achievements in research on gratitude, many questions have yet to be clarified. We believe that elucidating these doubts can contribute to the formulation of education policies, provide the reference for teachers' teaching, and correctly explain students' behavior. Previous studies have indicated that the benefactor's motives for conferring a benefit (Pelser, de Ruyter, Wetzels, Grewal, Cox, \& van Beuningen, 2015; Tsang, 2006b), the amount of effort exerted by the benefactor (Pelser, de Ruyter, Wetzels, Grewal, Cox, \& van Beuningen, 2015), and the benefactor's consciousness when conferring a favor (Tsang, 2006a) influence gratitude. However, the relationship between the benefactor and the beneficiary (e.g., parents and friends) is rarely examined. Therefore, the motive of this study is whether the gratitude levels of the beneficiary is the same after different benefactors confer a favor.

Based on the aforementioned research motive, the question awaiting to be answered by this study is as follows. If the favor conferred is the same, is the level of gratitude elicited the same regardless of who (e.g., parents and friends) is doing the favor?

\section{Implications of Gratitude and the Factors that Produce Gratitude}

Gratitude is a type of positive emotion (McCullough, Kimeldorf \& Cohen, 2008) that comes from the interaction between two parties, which we call the benefactor and the beneficiary. In this interaction, does the beneficiary feel grateful when the benefactor helps the beneficiary or does a favor? After reviewing the literature, this study found that eliciting gratitude is not only about conferring favors, but the following conditions must also be met.

- The benefactor's help comes at a cost for the benefactor during the helping process (McCullough, Kimeldorf \& Cohen, 2008; McCullough, Kilpatrick, Emmons \& Larson, 2001). If one's benefits come at the expense of others' hard work, one will be grateful (Pelser, de Ruyter, Wetzels, Grewal, Cox, \& van Beuningen, 2015). Expensive favors are more able to elicit gratitude than inexpensive favors (Pelser, de Ruyter, Wetzels, Grewal, Cox, \& van Beuningen, 2015).

- The benefactor provides help intentionally (McCullough, Kimeldorf \& Cohen, 2008; McCullough, Kilpatrick, Emmons \& Larson, 2001). Tsang (2006a) found that the party on the receiving end of the benefits is more grateful and have more positive reactions when the benefactor makes conscious efforts to benefit the other party than when the benefactor makes unconscious efforts.

- The help provided by the benefactor is non-obligatory (McCullough, Kilpatrick, Emmons \& Larson, 2001) or is voluntary (McCullough, Kimeldorf \& Cohen, 2008).

- The help provided by the benefactor is valuable to the beneficiary (McCullough, Kilpatrick, Emmons \& Larson, 2001). 
- The benefactor's motives for providing help come from a benevolent motive (Tsang, 2006b). Benevolent motives elicit more gratitude than self-serving motives (Pelser, de Ruyter, Wetzels, Grewal, Cox \& van Beuningen, 2015; Tsang, 2006b).

Although many factors influencing gratitude were compiled above and all are regarding the benefactor, there is a dearth of studies on the identity of the benefactor. To date, the study results are underdeveloped. The identity of the benefactor is the focus to be explored in this study.

\section{The Effect of the Source of Favors on Gratitude}

Favors from different sources may produce different gratitude's levels. Bar-Tal, Bar-Zohar, Greenberg, and Hermon (1977) found that in a condition of the same favors provided by someone, one is more grateful to a stranger, an acquaintance, and a friend than to a relative. In this study, the reasons about above findings are proposed according to the following four viewpoints, and the hypothesis regarding friends and parents as the benefactor of the college students is proposed.

\section{-Interest Viewpoint}

Trivers (1971) discusses gratitude from the viewpoint of interests and argued that the benefactor's interests gained by his/her altruistic behavior have a strong relationship with the beneficiary's gratitude. This viewpoint can be used to explain why college students have a higher level of gratitude to their friends, but a lower level of gratitude to their parents when receiving favors from parents and friends. Because parents and their child are a community of interest, when parents provide resources or help to their child, the resources or help expended is still within the parents' self-interest as long as the value produced by the child is greater than the cost expended by the parents. Therefore, in blood relationships, children feel less grateful for their parents' help. Based on the viewpoints of Trivers (1971) and Nowak and Roch (2007), we believe that help from parents elicit less gratitude, while help from friends elicit more gratitude.

\section{-Expectation Viewpoint}

Using the expectations of the beneficiary towards the benefactor as the foundation, Forster, Pedersen, Smith, McCullough, and Lieberman (2017) described the gratitude levels of the beneficiary and believe that when expectations are high, the threshold of benefits required to achieve gratitude is relatively high. Under this condition, the benefits are less likely to exceed the threshold, so gratitude is not easily formed. The college students in this study accepted the same help from parents and friends. They believe that their parents should help them, taking it for granted and having high expectations. However, they do not have such high expectations for their friends' help because their friends are not obligated, so they feel more grateful after receiving help from their friends. 
-Relationship Viewpoint

The relationship between the benefactor and the beneficiary has influence over gratitude. Unsworth, Turner, Williams, and Piccin-Houle (2010) found that in a relationship with high levels of trust, gratitude is less likely to be elicited because in such a relationship, both parties take the help for granted. Therefore, it is within the beneficiary's anticipation and less likely to surpass expectations when a benefit is conferred, so the beneficiary feels less grateful. In addition, college students' relationship with their parents is more trusting than their relationship with their friends. Using the aforementioned argument that under a relationship with trust, gratitude is less likely to occur, it can be explained why college students are less likely to feel grateful for their parents' help.

\section{-Social Norm Viewpoint}

Every country has different social norms. The same behavior may be within social norms in some countries but may be outside of social norms in other countries. Weinstein, DeHaan, and Ryan (2010) indicated that help given under autonomous motivation produces more gratitude than help given under introjected motivation; help given under introjected motivation is driven by social pressure, because society places blame on those who do not provide help and one may feel guilty. Helping behaviors that do not fall under social norms indicates that the helping behavior comes from the helper's own volition. Therefore, the beneficiary feels more grateful when the benefactor's motives for the helping behavior are autonomous. On the contrary, helpers who provide helping behaviors that fall under the social norms maybe only be doing so to conform to social norms and avoid social condemnation. Therefore, the beneficiary feels less grateful to the benefactor with introjected motivation. In addition, Li, Luo and $\mathrm{Fu}$ (2019) conducted two scenario studies in the context of charitable giving and found that when beneficiaries feel benefactor's less responsible to help them, the benefactor's intention is perceived as benevolent rather than utilitarian, leading beneficiaries to perceive the donation as being more helpful, thereby evoking their greater gratitude. Based on aforementioned logic, parents taking care of their child are conforming social norms and help that conforms to social norms is a matter of course, but a friend's help does not conform to social norms. Therefore, for college students, less gratitude is elicited by their parents' help than their friends' help.

Based on the aforementioned discussion, college students feel more grateful to their friends than their parents when their friends and parents provide the same help. We propose Hypothesis 1.

H1: When given the same help, college students have a higher level of gratitude to their friends, but a lower level of gratitude to their parents. 


\section{Al Macrothink}

\section{Research Methods and Results}

\subsection{Study 1}

Data collection in this study was conducted that the study sample first read the experimental text and then filled out the gratitude questionnaire. Questionnaires were randomly distributed to college students in Tainan, Kaohsiung and Pingtung cities. 800 questionnaires were sent out and 720 questionnaires were collected. After deleting incomplete questionnaires, this study obtained 681 valid questionnaires. Table 1 shows the profile of the study sample.

Table 1. The Sample of Study $1(\mathrm{~N}=681)$ : Sacrificing One's Life to Save Others

\begin{tabular}{|c|c|c|c|}
\hline & Type & $\mathrm{N}$ & Percentage \\
\hline \multirow[t]{6}{*}{ Grade } & Freshmen & 142 & 20.9 \\
\hline & Sophomore & 138 & 20.3 \\
\hline & Junior & 150 & 22.0 \\
\hline & Senior & 99 & 14.5 \\
\hline & Master's program & 126 & 18.5 \\
\hline & PhD's program & 26 & 3.8 \\
\hline \multirow[t]{2}{*}{ Gender } & Male & 233 & 34.2 \\
\hline & Female & 448 & 65.8 \\
\hline \multirow[t]{5}{*}{ Age } & $<20$ & 169 & 24.8 \\
\hline & $20 \leq$ age $<25$ & 359 & 52.7 \\
\hline & $25 \leq$ age $<30$ & 22 & 3.2 \\
\hline & $30 \leq$ age $<40$ & 43 & 6.3 \\
\hline & $40 \leq$ age & 88 & 12.9 \\
\hline \multirow{4}{*}{$\begin{array}{l}\text { Number of Siblings } \\
\text { (including themselves) }\end{array}$} & 1 & 107 & 15.7 \\
\hline & 2 & 265 & 38.9 \\
\hline & 3 & 208 & 30.5 \\
\hline & Over 4 & 101 & 14.8 \\
\hline \multirow[t]{9}{*}{ Institution Attended } & Literature & 111 & 16.3 \\
\hline & Law & 1 & 0.1 \\
\hline & Business & 241 & 35.4 \\
\hline & Medicine & 50 & 7.3 \\
\hline & Agriculture & 1 & 0.1 \\
\hline & Engineering & 8 & 1.2 \\
\hline & Science & 28 & 4.1 \\
\hline & Education & 84 & 12.3 \\
\hline & Others & 157 & 23.1 \\
\hline \multirow[t]{6}{*}{ Economic Sources } & Completely from family & 181 & 26.6 \\
\hline & Mostly from family & 167 & 24.5 \\
\hline & $\begin{array}{l}\text { Split evenly between } \\
\text { family and themselves }\end{array}$ & 105 & 15.4 \\
\hline & Mostly from themselves & 84 & 12.3 \\
\hline & $\begin{array}{l}\text { Completely from } \\
\text { themselves }\end{array}$ & 139 & 20.4 \\
\hline & Other & 5 & 0.7 \\
\hline
\end{tabular}

The gratitude questionnaire of this study was a semantic differential scale with 10 -point. The format was described as follows. 
Very ungrateful $1-2-3-4-5-6-7-8-9-10$ Very grateful

In this study, the 800 participants in the sample were divided into two groups (each group had 400 participants) in a random manner. Half read Version A of the experimental text while the other half read Version B. Among the 681 valid questionnaires in the study 1, $354(52 \%)$ participants read Version A while 327 (48\%) participants read Version B. Before the experimental text was presented to the participants, the following guidelines were shown: please read the text three times and then answer the questions. The purpose of reading three times is to immerse the participants in the plot. The first group of college students (Version A's participants) read the experimental text in which they were angling with their parents by the river bank and had very unfortunately fell in the water until their parents saved them just at the time of danger. The second group of college students read the experimental text in which they were angling with their friends by the river bank and had unfortunately fell in the water until their friends saved them just at the time of danger. After reading the text three times, the college students were asked to answer questionnaires pertaining to their gratitude towards their parents (Version A's participants) or friends (Version B's participants).

- The content of Version A:

Fishing is your hobby. You often fish together with your family. After a morning of heavy rainfall, the skies cleared in the afternoon. You and your parents go angling by the river bank, but being careless, you cross the warning line. It is slippery from the rain and you unfortunately fall in the river. The water is deep and rapid. At the time, it was very dangerous. If no one had saved you, you would have died. After you wake up, you're already lying by the bank and hear the ambulance's sirens. Just at the time of danger, your parents had saved you, putting your life above theirs. They had sustained cuts by branches in the river. After the ambulance arrives, you and your parents get in together.

- The content of Version B:

Fishing is your hobby. You often fish together with your friends. After a morning of heavy rainfall, the skies cleared in the afternoon. You and your two friends go angling by the river bank, but being careless, you cross the warning line. It is slippery from the rain and you unfortunately fall in the river. The water is deep and rapid. At the time, it was very dangerous. If no one had saved you, you would have died. After you wake up, you're already lying by the bank and hear the ambulance's sirens. At the time of danger, your two friends had saved you, putting your life above theirs. They had sustained cuts by branches in the river. After the ambulance arrives, you and your two friends get in together.

Since the nature of the experiment is gratitude, the text must be designed to be able to elicit gratitude. The reasons for the design of the experimental text are as follows. Theory indicates that the conditions for gratitude include that the benefactor must confer the favor to the beneficiary, the favor given by the benefactor must be what the beneficiary thinks is 
important and necessary, the motive for the favor given by the benefactor must be selfless, and the benefactor must make considerable effort to give favors. We have taken the above conditions into consideration and put it in the narrative of the text. "being rescued after falling in the water" illustrates the favor; "The water is deep and rapid. At the time, it was very dangerous. If no one had saved you, you would have died" indicates the importance of the favor; "They sustained cuts by branches in the river" shows that their motives are selfless; "putting your life above theirs" indicates that a relative amount of effort was exerted. To avoid other factors interfering with the study results, the content of the experimental texts was the same with the exception of the benefactor's identity (parents or two friends). The number of benefactors was two for both texts.

For the valid questionnaires, we perform the independent-sample $t$ test to verify whether the levels of gratitude elicited by help from their friends and help from their parents have a significant difference. If there is a significant difference, the score of the level of gratitude was observed to determine which had lower or higher levels of gratitude: gratitude towards parents or gratitude towards friends.

The verification results of the independent-samples $t$ test are shown in Table 2. First, Levene's test was performed to assess the equality of variances for gratitude levels in the two groups. The results showed that the F value was 0.120 and the significant level was 0.729 ( $p$ $>0.05)$, meanng that the variances for gratitude levels in the two groups were the same. Therefore, in Table 2, we observed the $t$ value and $p$ value in the row of showing the equal variance. The results showed that the $t$ value was 0.515 , the degree of freedom was 679 , and the $p$ value was 0.606 , which did not reach the significant level of $p<0.05$, meaning that had no significant difference in the level of gratitude of college students whether it was the help of their parents or their friends. Hypothesis 1, "When given the same help, college students have a higher level of gratitude to their friends, but a lower level of gratitude to their parents", did not gain empirical support from this study. However, observing the average score of gratitude between the two groups, the average for accepting help from parents was 9.56 while the average for accepting help from friends was 9.52; both are relatively high.

Table 2. $T$ Test for the Gratitude Means between Parents and Friends of Study 1 (Sacrificing One's Life to Save Others)

\begin{tabular}{|c|c|c|c|c|c|c|}
\hline & \multicolumn{2}{|c|}{$\begin{array}{l}\text { Levene's Test for } \\
\text { Equality of Variances }\end{array}$} & \multicolumn{4}{|c|}{$\mathrm{T}$ test for Equal Means } \\
\hline & $\mathrm{F}$ & Significance & $\mathrm{t}$ & $\begin{array}{l}\text { Degree of } \\
\text { Freedom }\end{array}$ & $\begin{array}{l}\text { Significance } \\
\text { (two-tailed) }\end{array}$ & $\begin{array}{c}\text { Mean } \\
\text { Difference }\end{array}$ \\
\hline Equal Variance & .120 & .729 & .515 & 679 & .606 & .043 \\
\hline \multicolumn{7}{|l|}{ Assumed } \\
\hline Equal Variance Not & & & .515 & 674.516 & .606 & .043 \\
\hline Assumed & & & & & & \\
\hline
\end{tabular}


4.2 Study 2

Table 3. The Sample of Study $2(\mathrm{~N}=460)$ : Hospital Care

\begin{tabular}{|c|c|c|c|}
\hline & Type & $\mathrm{N}$ & Percentage \\
\hline \multirow[t]{6}{*}{ Grade } & Freshmen & 74 & 16.1 \\
\hline & Sophomore & 86 & 18.7 \\
\hline & Junior & 98 & 21.3 \\
\hline & Senior & 73 & 15.9 \\
\hline & Master's program & 108 & 23.5 \\
\hline & PhD’s program & 21 & 4.6 \\
\hline \multirow[t]{2}{*}{ Gender } & Male & 232 & 50.4 \\
\hline & Female & 228 & 49.6 \\
\hline \multirow[t]{5}{*}{ Age } & age $<20$ & 92 & 20.0 \\
\hline & $20 \leq$ age $<25$ & 241 & 52.4 \\
\hline & $25 \leq$ age $<30$ & 17 & 3.7 \\
\hline & $30 \leq$ age $<40$ & 36 & 7.8 \\
\hline & $40 \leq$ age & 74 & 16.1 \\
\hline \multirow{4}{*}{$\begin{array}{l}\text { Number of Siblings } \\
\text { (including themselves) }\end{array}$} & 1 & 133 & 28.9 \\
\hline & 2 & 168 & 36.5 \\
\hline & 3 & 112 & 24.3 \\
\hline & Over 4 & 47 & 10.2 \\
\hline \multirow[t]{9}{*}{ Institution Attended } & Literature & 47 & 10.2 \\
\hline & Law & 41 & 8.9 \\
\hline & Business & 83 & 18.0 \\
\hline & Medicine & 34 & 7.4 \\
\hline & Agriculture & 38 & 8.3 \\
\hline & Engineering & 71 & 15.4 \\
\hline & Science & 43 & 9.3 \\
\hline & Education & 60 & 13.0 \\
\hline & Others & 43 & 9.3 \\
\hline \multirow[t]{6}{*}{ Economic Resources } & Completely from family & 94 & 20.4 \\
\hline & Mostly from family & 110 & 23.9 \\
\hline & $\begin{array}{l}\text { Split evenly between } \\
\text { family and themselves }\end{array}$ & 58 & 12.6 \\
\hline & Mostly from themselves & 86 & 18.7 \\
\hline & $\begin{array}{l}\text { Completely from } \\
\text { themselves }\end{array}$ & 108 & 23.5 \\
\hline & Others & 4 & .9 \\
\hline
\end{tabular}


Study 1 found that there was no significant difference in the gratitude levels of college students accepting help from their parents and help from their friends. Upon review, one possible reason may be that the setting of the experimental text is a life-threatening event (sacrificing one's life to save others) for the benefactor and the beneficiary; regardless of who lends a helping hand to the drowning person, the drowning person will not only feel grateful, but tremendously grateful (over 9.5 on a 10-point scale). In response to this problem, we conducted Study 2 and changed the context from a life-threatening event to that of hospital care. For the purpose of re-verifying H1, another sample was extracted (a different sample from Study 1) to collect data on gratitude.

Study 2 used the same steps as the study 1. Additionally, questionnaires were randomly distributed to college students in Tainan, Kaohsiung and Pingtung cities. 500 questionnaires were sent out and 472 questionnaires were collected. After deleting incomplete questionnaires, this study obtained 460 valid questionnaires.

Table 3 displays the sample distribution of the study 2 .

The experimental text designed by Study 2 was divided into Version C and Version D according to the identity of the benefactor (parents and friends, respectively). First, we provided one of two experimental texts (Version C and Version D) to participants to read it, and then guided them to fill out the gratitude questionnaire.

We used a 10-point semantic differential scale (as below) to assess the gratitude level of college students after accepting their parents' or friends' help.

Very ungrateful $1-2-3-4-5-6-7-8-9-10$ Very grateful

- The content of Version C:

My body is very healthy, and I have almost no illness. Because of this, I neglect to take care of my body. I enjoyed a vacation some days ago, and I crazily ate and drank at noon. It was super refreshing, but at three o'clock in the afternoon that day, I started to feel upset in my stomach. I hurried back to the place where I rented the house. After I went back there, start vomiting and diarrhea, and there was cramping. I called my parents to ask their helps, $\underline{m y}$ parents immediately put down the work that were doing, rushed over and drove me to the emergency department of the hospital. The doctor ordered some medical inspections for me, and then according to the inspection report, the doctor did some treatments for me. The doctor said that I need to be hospitalized and reminded me and my parents to be careful of my falling because I was very weak, especially when getting in and out of bed. Because there was no ward at the time, we needed to wait for the ward, so we stayed in the emergency room for one night. My parents could only sit in the chair and stayed with me for one night. After noon the next day, we moved to the general ward. I was hospitalized for three days in the general ward. After the three days, I was almost recovered and then my parents accompanied me to leave the hospital. My parents took care of me personally for four days in the hospital without any complaints. 
- The content of Version D:

My body is very healthy, and I have almost no illness. Because of this, I neglect to take care of my body. I enjoyed a vacation some days ago, and I crazily ate and drank at noon. It was super refreshing, but at three o'clock in the afternoon that day, I started to feel upset in my stomach. I hurried back to the place where I rented the house. After I went back there, start vomiting and diarrhea, and there was cramping. I called my two friends to ask their helps, $\underline{m y}$ two friends immediately put down the work that were doing, rushed over and drove me to the emergency department of the hospital. The doctor ordered some medical inspections for me, and then according to the inspection report, the doctor did some treatments for me. The doctor said that I need to be hospitalized and reminded me and my two friends to be careful of my falling because I was very weak, especially when getting in and out of bed. Because there was no ward at the time, we needed to wait for the ward, so we stayed in the emergency room for one night. My two friends could only sit in the chair and stayed with me for one night. After noon the next day, we moved to the general ward. I was hospitalized for three days in the general ward. After the three days, I was almost recovered and then my two friends accompanied me to leave the hospital. My two friends took care of me personally for four days in the hospital without any complaints.

Among the 460 valid questionnaires in the study 2, $230(50 \%)$ participants read Version C and $230(50 \%)$ read Version D. Before the experimental text was presented to the participants, the following guidelines were shown: please read the text three times and then answer the questions. The purpose of reading three times is to immerse the participants in the plot. The first group of college students (Version C's participants) read text that stated their parents are taking care of the subject in the hospital while the second group of college students (Version D's participants) read text that stated their friends are taking care of the subject in the hospital. After reading the text three times, the participants were asked to answer questionnaires regarding their gratitude towards their parents (Version C's participants) or friends (Version D's participants).

The same points were considered as Study 1. Because the nature of the experiment is gratitude, the text must be designed to be able to elicit gratitude. The following explains the reasons for the design of the experimental text. Theory indicates that the conditions for gratitude include that the benefactor must confer the favor to the beneficiary, the favor given by the benefactor must be what the beneficiary thinks is important and necessary, the motive for the favor given by the benefactor must be selfless, and the benefactor must make considerable effort to give favors. We have taken the above conditions into consideration and put it in the narrative of the text. "drove me to the emergency department of the hospital", "stayed with me for one night", and "took care of me personally for four days" illustrate the favor; “... vomiting and diarrhea, and there was cramping... I need to be hospitalized and ... to be careful of my falling because I was very weak, especially when getting in and out of bed" shows that the participant needs help to illustrate the importance of the favor which the benefactor provided to the beneficiary; "took care of me personally for four days in the hospital without any complaints" demonstrates that the benefactor's motives are selfless; 
"immediately put down the work that were doing, rushed over and drove me to the emergency department of the hospital", "could only sit in the chair and stayed with me for one night", and "took care of me personally for four days" indicate that a relative amount of effort was exerted. To avoid other factors interfering with the study results, the content of the experimental texts was the same only except the benefactor's identity (parents or two friends). The number of benefactors was two for both texts.

For the valid questionnaires, we perform the independent-sample $t$ test to verify whether the levels of gratitude elicited by help from their friends and help from their parents have a significant difference. If there is a significant difference, the mean score of the level of gratitude was observed to determine that the help from parents or from friends could elicit the higher gratitude. Our findings are as shown in Table 4. First, whether two groups had a same gratitude variance was tested by Levene's test. The test results showed that the F value was 0.468 , and the significance level was 0.494 ( $\mathrm{p}>0.05$ ), meaning we could assume equal variances for gratitude levels in the two groups. Therefore, we observed the $t$ value and $p$ value in the row showing "equal variance assumed" in Table 4. The $t$ value was -12.318 , the degree of freedom was 458, and the $p$ value was 0.000 , which reached the significant level of $p<0.001$. Based on the mean score of gratitude in the two groups (Table 5), accepting parents' help was 7.80, while accepting friends' help was 9.10, meaning that college students were more grateful towards their friends than their parents when providing the same help. Hypothesis 1, which posits that when given the same help, college students have a higher level of gratitude to their friends, but a lower level of gratitude to their parents, gained empirical support from Study 2.

Table 4. $\mathrm{T}$ Test for the Gratitude Means between Parents and Friends of Study 2 (Hospital Care)

\begin{tabular}{|c|c|c|c|c|c|c|}
\hline & \multicolumn{2}{|c|}{$\begin{array}{c}\text { Levene's Test for } \\
\text { Equality of Variances }\end{array}$} & \multicolumn{4}{|c|}{ T test for Equal Means } \\
\hline & $\mathrm{F}$ & Significance & $\mathrm{t}$ & $\begin{array}{l}\text { Degree of } \\
\text { Freedom }\end{array}$ & $\begin{array}{l}\text { Significance } \\
\text { (two-tailed) }\end{array}$ & $\begin{array}{c}\text { Mean } \\
\text { Difference }\end{array}$ \\
\hline $\begin{array}{l}\text { Equal Variance } \\
\text { Assumed }\end{array}$ & .468 & .494 & -12.318 & 458 & .000 & -1.300 \\
\hline $\begin{array}{l}\text { Equal Variance Not } \\
\text { Assumed }\end{array}$ & & & -12.318 & 456.715 & .000 & -1.300 \\
\hline
\end{tabular}

Table 5. The Mean of Gratitude for Parents and Friends of Study 2 (Hospital Care)

\begin{tabular}{llllll}
\hline & Group & $\mathrm{N}$ & Mean & $\begin{array}{l}\text { Standard } \\
\text { Deviation }\end{array}$ & $\begin{array}{l}\text { Standard Error } \\
\text { of the Mean }\end{array}$ \\
\hline Gratitude & Parents & 230 & 7.80 & 1.157 & .076 \\
& Friends & 230 & 9.10 & 1.098 & .072 \\
\hline
\end{tabular}




\section{Conclusion}

In the past, some studies had confirmed that some factors related to the benefactor have an impact on gratitude, but the influence of the identity of the benefactor on gratitude was still unclear. Two studies were conducted to verify whether college students feel more grateful to their friends than their parents when the same help is given by both. Data was collected through the participants first reading the experimental text then answering the questionnaire. The results are shown in Table 6. Study 1 with the experiment of sacrificing one's life to save others without supporting H1, which found that there was no significant difference in college students' gratitude toward their friends and their parents when both give the same help and that they had high levels of gratitude toward both. However, study 2 with the experiment of hospital care supports H1, which found that college students have a higher level of gratitude to their friends, but a lower level of gratitude to their parents, when their parents and friends give the same help. The difference between Study 1 and Study 2 lies in the degree of effort exerted when the benefactor confers the favor and the importance of the favor to the beneficiary. In Study 1, the benefactor exerted a large amount of effort and the favor was very important to the beneficiary, while the benefactor exerted a moderate amount of effort and the favor was of moderate importance to the beneficiary in Study 2; both effort and importance in Study 2 decreased. Therefore, the study results show that college students are not necessarily more grateful to their friends than their parents (depending on effort level and importance level). However, the interest viewpoint of Trivers (1971), the expectation viewpoint of Forster, Pedersen, Smith, McCullough, and Lieberman (2017), the relationship viewpoint of Unsworth, Turner, Williams, and Piccin-Houle (2010), and the social norm viewpoint of Weinstein, DeHaan, and Ryan (2010) argued that gratitude towards friends is higher than gratitude towards parents, which is inconsistent with the findings of Study 1 but consistent with those of Study 2. Therefore, when the benefactor makes a large amount of effort to confer the favor and the favor is very important to the beneficiary, the beneficiary's response to the parents' this kind of favor is not bound by interests, expectations, relationship, and social norms; the parents' help is not taken for granted, so the beneficiary is still very grateful towards their parents. This finding can complement the shortcomings in the theory of past research, making it more complete.

Table 6. Overview of Study Results

\begin{tabular}{lll}
\hline Hypothesis & Empirical Results & Condition \\
\hline $\begin{array}{l}\text { When given the same help, } \\
\text { college students have a higher } \\
\text { level of gratitude to their friends, } \\
\begin{array}{l}\text { but a lower level of gratitude to } \\
\text { their parents. }\end{array}\end{array}$ & $\begin{array}{l}\text { Study 1: not supported (no significant } \\
\text { difference) }\end{array}$ & Very important help \\
\hline
\end{tabular}




\section{Suggestions}

\subsection{Suggestions for Practice}

This study found that if the benefactor exerts a large amount of effort when conferring the favor and the favor is very important to the beneficiary, college students feel the same amount of gratitude towards their parents and friends and the level of gratitude felt is very high. However, if the effort and importance are slightly lower and the same help was given by parents and friends, college students have a higher level of gratitude to their friends, but a lower level of gratitude to their parents. This shows that it is a harder task for students to be grateful to their parents. Therefore, we suggest schools to strengthen college students' gratitude education towards their parents, emphasizing the hard work parents do for their children, so that college students can cherish and even be grateful for their parents' efforts, in order to get the same positive results as gratitude for their friends' efforts.

\subsection{Suggestions for Future Research}

In the comparison between college students' gratitude towards their friends and parents in this study, there are still some shortcomings. Previous studies on gratitude showed that the benefactor must exert effort and the favor must be important to the beneficiary in order to elicit gratitude. Under circumstances that elicit gratitude, the benefactor's effort to convey the favor can be divided into two groups: high effort and moderate effort while the importance of the favor to the beneficiary can be divide into two groups: high importance and moderate importance for a total of four different scenarios. This study only explored the pairing of high effort with high importance in Study 1 and moderate effort with moderate importance in Study 2 and did not explore the other two scenarios. Therefore, we suggest that future studies explore the other two scenarios, the first of which is that the benefactor exerts high effort and the favor is of moderate importance to the beneficiary while the second scenario is that the benefactor exerts moderate effort and the favor is of high importance to the beneficiary. In these two scenarios, gratitude towards parents and friends can be compared. The results can also be compared with this study to get a clearer picture on gratitude towards parents and friends.

\section{Acknowledgments}

The author is grateful to Ministry of Science and Technology in Taiwan for the financial support (MOST 106-2410-H-024-012-SSS).

\section{References}

Bar-Tal, D., Bar-Zohar, Y., Greenberg, M. S., \& Hermon, M. (1977). Reciprocity behavior in the relationship between donor and recipient and between harm-doer and victim. Sociometry, 40(3), 293-298. https://doi.org/10.2307/3033537

Forster, D. E., Pedersen, E. J., Smith, A., McCullough, M. E., \& Lieberman, D. (2017). 
Benefit valuation predicts gratitude. Evolution and Human Behavior, 38(1), 18-26. https://doi.org/10.1016/j.evolhumbehav.2016.06.003

Li, Y., Luo, L., \& Fu, J. (2019). Benefactor intention, perceived helpfulness, and personal responsibility influence gratitude and indebtedness. Social Behavior and Personality, 47(2), 1-15. https://doi.org/10.2224/sbp.7481

McCullough, M. E., Kilpatrick, S. D., Emmons, R. A., \& Larson, D. B. (2001). Is gratitude a moral affect? Psychological Bulletin, 127(2), 249-266. https://doi.org/10.1037/0033-2909.127.2.249

McCullough, M. E., Kimeldorf, M. B., \& Cohen, A. D. (2008). An adaptation for altruism? The social causes, social effects, and social evolution of gratitude. Current Directions in $\begin{array}{lll}\text { Psychological } & \text { Science, } & \text { 281-285. }\end{array}$ https://doi.org/10.1111/j.1467-8721.2008.00590.x

Nowak, M., \& Roch, S. (2007). Upstream reciprocity and the evolution of gratitude. Proceedings of the Royal Society of London, Series B: Biological Sciences, 274, 605-609. https://doi.org/10.1098/rspb.2006.0125

Pelser, J., de Ruyter, K., Wetzels, M., Grewal, D., Cox, D., van Beuningen, J. (2015). B2B channel partner programs: Disentangling indebtedness from gratitude. Journal of Retailing, 91(4), 660-678. https://doi.org/10.1016/j.jretai.2015.05.006

Trivers, R. L. (1971). The evolution of reciprocal altruism. Quarterly Review of Biology, 46(1), 35-57. https://doi.org/10.1086/406755

Tsang, J. A. (2006a). Gratitude and prosocial behavior: An experimental test of gratitude. Cognition and Emotion, 20(1), 138-148. https://doi.org/10.1080/02699930500172341

Tsang, J. A. (2006b). The effects of helper intention on gratitude and indebtedness. Motivation and Emotion, 30(3), 199-205. https://doi.org/10.1007/s11031-006-9031-z

Unsworth, K. L., Turner, N., Williams, H. M., \& Piccin-Houle, S. (2010). Giving thanks: The relational context of gratitude in postgraduate. Studies in Higher Education, 35(8), 871-888. https://doi.org/10.1080/03075070903348396

Weinstein, N., DeHaan, C. R., \& Ryan, R. M. (2010). Attributing autonomous versus introjected motivation to helpers and the recipient experience: Effects on gratitude, attitudes, and well-being. Motivation and Emotion, 34(4), 418-431. https://doi.org/10.1007/s11031-010-9183-8

\section{Copyright Disclaimer}

Copyright for this article is retained by the author(s), with first publication rights granted to the journal.

This is an open-access article distributed under the terms and conditions of the Creative Commons Attribution license (http://creativecommons.org/licenses/by/3.0/). 